\title{
Web-Based Weapons of Mass Destruction Training for Transit Police
}

Lori A. Magda, Allison N. Canton, and Robyn R.M. Gershon Mailman School of Public Health, Columbia University

\begin{abstract}
In response to increased terrorist attacks on mass transit systems worldwide, emergency planning and security efforts have intensified. One of the most important planning elements is the provision of training for first-response personnel. Yet few terrorism-related training programs specific to the mass transit sector are available. To address this unmet need, a web-based weapons of mass destruction (WMD) simulation training program, specifically designed for transit police, was recently developed, implemented, and evaluated. Results indicate that this program was effective in improving transit police officers' ability to recognize and respond to WMD simulations.
\end{abstract}

\section{Introduction}

Terrorist attacks targeting transit infrastructure document the inherent vulnerability of these systems. They also underscore the important role of emergency preparedness in minimizing morbidity, mortality, and structural damage (Sahm 2006; Okumura, Ninomiya, and Ohta 2003; Bolling et al. 2007; Intelligence and Security Committee 2006). Beyond the immediate impact on the intended target, "transit terrorism" can instill fear and dread among the transit ridership and public at large (Litman 2005). This fear may translate into reduced ridership with resultant 
economic, social, and political ramifications (Litman 2005; Dolnik 2007). While any multi-passenger mode of conveyance may be the target of transit terrorism, historically, public transportation buses have most often been attacked. Between 1920 and 2000, 40 percent of terrorist attacks worldwide involved buses, with explosives most commonly used (Jenkins and Gersten 2001). Heavy rail, including commuter trains and subways, has also been the target of transit terrorism. High passenger volumes, predictable peak periods (e.g., rush-hour), easy accessibility, anonymity, and lack of security screening of passengers make all forms of mass transit potential targets of terrorism (Dolnik 2007; Waugh 2004; Fink, Taylor, and Loukaitou-Sideris 2005; Jenkins and Gersten 2001).

In 1995, the first large-scale WMD attack involving mass transit took place in Tokyo. Shinrikyo terrorists released sarin gas on the subway system during rush hour, resulting in 12 deaths and thousands of injuries (Sahm 2006). Disorganized command and miscommunication at the scene increased the risk of exposure to passengers, transit workers, and first responders. Exposed first responders even served as a source of secondary exposure to others, including those waiting to be treated in hospital emergency rooms (Jenkins and Gersten 2001). Following this attack, major changes were implemented in Japan to enhance emergency response to $\mathrm{WMD}$ attacks. Scene demarcation, personal protective equipment, information sharing and coordination, and education and training are now standard features of Japan's chemical disaster response plan (Okumura, Ninomiya, and Ohta 2003).

Nine years later, on March 11, 2004, the Red Nacional de Ferrocarriles Españoles (RENFE) rail system in Madrid was the target of transit terrorism. The attack was perpetrated by Al Qaeda operatives, who detonated remotely-controlled explosives (Sahm 2006). Although Madrid's emergency response plan was put into effect within an hour of the attack, the fatality rate was high, with close to 200 individuals killed and over 1,000 others injured (Bolling et al. 2007). Officials reported that the rapid and coordinated efforts of transit police, municipal agencies, and the national army helped to prevent even more deaths and casualties. Since the attacks, closed-circuit television (CCTV) monitoring of the RENFE transit system has greatly increased, along with improvements to its police training program (Taylor et al. 2005).

Another country that has experienced large-scale transit terrorist attacks in recent years is Great Britain. Historically, the London underground and commuter rail system has been targeted by the Irish Republican Army (IRA) terrorist group. Consequently, the transit system has long been the focus of intense, ongoing counter- 
terrorism activities (Jenkins and Gersten 2001). In spite of this high level of security, the system was breached. On July 7, 2005, suicide bombers detonated explosives on subway trains and a double-decker bus during the morning commute in London (Sahm 2006). Fifty-two individuals were killed and approximately 700 were injured. Following these events, a report by Great Britain's Security and Intelligence Committee noted that while the nation's intelligence agencies and security infrastructure, including law enforcement and counter-terrorism units, were not liable for the attack, improvements to security were absolutely necessary (Intelligence and Security Committee 2006). In response, counter-terrorism efforts for mass transit further intensified. More comprehensive national and local emergency management plans were developed, including better training on recognition and response to possible chemical, biological, radiological, nuclear, and explosives (CBRNE) terrorism attacks (Home Office of the United Kingdom 2009).

In response to transit terrorism, many other transportation systems worldwide similarly improved their basic security measures. More extensive controls, improved communications, and increased presence of law enforcement on trains, platforms, and stations are standard in many systems. Surveillance equipment is increasingly common on all forms of mass transit. In addition, passenger screening and public awareness campaigns also have been instituted. Education of transit workers is also a priority for many transit systems (Sahm 2006). However, all of these preventive measures require substantial financial resources. Anti-terrorism funding is limited and in demand by many different sectors. For example, in the United States, improvements to transit security were made in the wake of the September 11 attacks, but the bulk of the terrorism preparedness and response funding focused primarily on aviation security (Waugh Jr. 2004; Office of the New York State Comptroller 2008).

Further mass transit security improvements are planned for the U.S., but increased costs and competing needs have led to delays. A good case in point is the security funding constraints faced by the Metropolitan Transit Authority (MTA), which oversees the mass transit system connecting New York City (NYC) to Long Island and Connecticut. MTA security increased dramatically following the World Trade Center attack, which destroyed 1,400 feet of subway track along 4 subway lines and led to the closure of 11 stations (Jenkins and Edwards-Winslow 2003; Mammen 2007). Additional security measures were implemented in NYC following the London terrorist bombings (Office of the New York State Comptroller 2006). Currently, the proposed MTA capital security plan budget is enormous, with 
projected costs in excess of $\$ 740$ million for the first of two phases (Office of the New York State Comptroller 2008). Other security improvements, including training, continue to be expensive. Therefore, financial constraints make it even more important for training programs to be cost-effective.

One low-cost training method that is increasingly popular is the web-based program. This format is especially suitable for incorporating simulated scenarios, that is, simulations of real events. Because simulations require decision making on the part of the learner, with feedback immediately given, students are more engaged and learning is enhanced (Cole 1994). Classroom-based simulation training programs have been successfully used to educate first responders and healthcare providers on a variety of topics (Subbarao et al. 2006; Summerhill et al. 2008; Idrose et al. 2007), and the adaptation of simulation exercises into the web-based format is relatively simple. Not only are simulations well-suited for emergency preparedness training, but the web-based platform is an efficient method for training large numbers of students.

To address the need for low-cost, effective training of transit police officers, the study team developed, implemented, and evaluated a state-of-art web-based simulation training program using a pre-post intervention study design.

\section{Methods}

\section{Human Subjects Protection}

The study protocol was approved by the Columbia University Medical Center Institutional Review Board (IRB), State University of New York College of Optometry IRB, and the Human Research Protection Office of the U.S. Army Medical Research and Materiel Command. All of the subjects provided informed consent prior to participation.

\section{Curriculum Development}

A Curriculum Development Team, representing experts in WMD, emergency preparedness, emergency medicine, and transit security, was formed. The resulting training curriculum reflected both local and national policies and procedures on WMD recognition and response. The curriculum consisted of two training modules: (1) an introduction to basic WMD knowledge and event detection, and (2) presentation of three simulation scenarios with embedded test items. Each of the scenarios presented potential terrorist-related events occurring in major mass transit transfer stations. The scenarios addressed three different types of events: 
a sarin gas release, an anthrax release, and an explosion of a radiological dispersal device (i.e., "dirty bomb").

During the simulations, participants were presented with decision points in which they were requested to choose a course of action. Participants choosing correctly advanced through the story line. Those with incorrect responses were provided with the correct answer and an explanation, and directed to an online resource for additional information. The training program was pilot-tested on police personnel, and changes were made to both the training modules and assessment tools based on their responses and suggestions.

\section{Module \& Scenario Adaptation}

The modules and scenarios were finalized in PowerPoint and then adapted for the project website using Adobe Photoshop ${ }^{\circledR}$ and Adobe Dreamweaver ${ }^{\circledR}$ software for module design, development, and deployment. The programming languages used were XHTML for markup, CSS for layout, and PHP for MySQL database interaction, dynamic content, and data validation. JavaScript ${ }^{\mathrm{tm}}$ also was used for client-side data validation. User tracking and reports were available as dynamically-generated Microsoft Excel ${ }^{\circledR}$ files. The online version of the modules also was pilot-tested for ease of use. (Copies of the training program in Microsoft PowerPoint ${ }^{\circledR}$ format and all study materials may be obtained at no cost from the corresponding author.)

\section{Study Population}

The Metropolitan Transit Authority Police Department (MTAPD) is the agency that polices the Metro-North Railroad, the Long Island Rail Road, and the Staten Island Railway. The MTAPD has jurisdiction in 14 counties and 2 states (NY and CT) (Metropolitan Transportation Authority 2009), which includes over 4,500 square miles. While it is primarily responsible for the commuter railroad in these two states, it has jurisdiction over the counties through which the trains run. In 2007, the MTA recorded over three billion passenger-rides, the highest of all transportation systems in the U.S. (American Public Transportation Association).

At the time of participant recruitment, the MTAPD employed approximately 550 officers. The training program was distributed to the entire MTAPD police force (nine districts) in January 2008. It was accompanied by an email from a high ranking officer of the MTAPD that encouraged all officers to participate. Recruitment was coordinated by each district administrator, and data collection continued until June 1, 2008. 


\section{Measures to Increase Response Rate}

Participants who did not complete the entire training program after initially registering were sent weekly reminders. A similar approach was taken for the onemonth follow-up questionnaire. Those who completed all three phases of testing were eligible to win an iPod Nano (odds of winning were 1:100). Any request to be removed from the email list was promptly honored.

\section{Assessment Measures}

To determine the effectiveness of the training program, assessment tools (i.e., pre-test, post-test, one-month follow-up test, and program evaluation) were developed and implemented. The pre-test was given before the training program and the post-test and evaluation immediately after, and the follow-up was given one month later. Key outcome variables included change in knowledge from the pre-test to post-test and from the pre-test to follow-up. The overall 13-item knowledge scale consisted of 2 subscales: WMD recognition (8 items) and WMD response knowledge ( 5 items) (see Table 1 for a description of the items). An internal consistency estimate of standardized responses to the overall knowledge scale yielded a Cronbach alpha of $0.62(95 \% \mathrm{Cl}=0.57-0.67)$. For the recognition subscale and response subscale, internal consistency estimates of standardized responses yielded Cronbach alphas of $0.55(95 \% \mathrm{Cl}=0.48-0.60)$ and $0.38(95 \%$ $\mathrm{Cl}=0.29-0.46$ ), respectively. The effectiveness of the training was determined by comparing pre-test to post-test scores and pre-test to follow-up test scores. Longterm retention was measured by comparing pre-test to follow-up test scores.

\section{Table 1. Description of WMD* Knowledge Items}

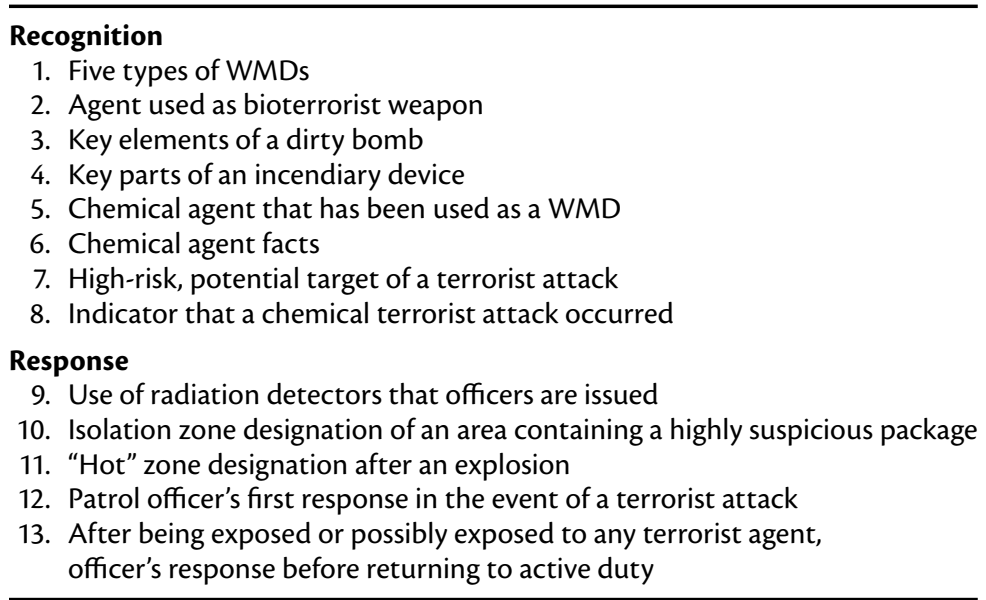

*WMD $=$ Weapon of Mass Destruction 


\section{Data Analysis}

A total of 540 individuals participated in the baseline assessment, online training, and post-test. Questionnaires missing substantial amounts of data on the pre-test and post-test or who did not provide consent were excluded from the analysis, resulting in a final sample of 502 participants (greater than $90 \%$ of the total available sample). Roughly one-fifth of the sample $(22 \%, n=108)$ completed the one-month follow-up. All data were entered into a database and then reviewed by a data manager to ensure accuracy of data entry. Data editing was followed by basic descriptive analysis of the data, including the calculation of means, medians, percentages, proportions, and standard deviations. Level of significance was set at an alpha level of 0.05 , two-tailed. Dependent $t$-tests were used to detect significant mean differences in scores for all scales from (1) pre-test to post-test, to assess increase in knowledge, (2) post-test to follow-up test, to assess knowledge retention, and (3) pre-test to follow-up test, to assess net gain in knowledge. Prior to analysis, assumptions for normality and equal variances were tested. The distributions of all sample groups were consistent with populations that are normal. Effect size was calculated using Cohen's (1988) d statistic (Cohen 1988). Pearson's chi-squared tests were used to test the significance of relations between categorical items. Odds ratios were calculated where appropriate. All analyses were conducted using SPSS 16.0.1 (SPSS Inc. 2008).

\section{Results}

Participants ( $\mathrm{N}=502)$ completing the pre-post phases of the study represented all districts of the MTAPD. Most respondents were male (90\%), with an average age of 39 years (ranging from 23 to 61 years). A majority (91\%) reported at least some college or higher levels of education. Most (81\%) participants were police officers assigned to patrol units, although $19 \%$ were of higher rank (e.g., sergeant, detective lieutenant, etc.). Average tenure with the MTA in any capacity was 9.4 years. Many participants (77\%) had received prior WMD training and, of these, 53 percent reported 6 hours or more of actual prior WMD training. However, almost a quarter of the sample reported no prior WMD training. Over a third of the sample (37\%) had actual prior large-scale disaster or WMD response experience. See Table 2 for a summary of demographic information. 
Table 2. Description of the Sample, MTAPD ( $\mathbf{N}=502)$

\begin{tabular}{lr} 
Characteristics & $\begin{array}{c}\mathbf{n} \\
\text { (\% reporting)* }^{*}\end{array}$ \\
\hline Gender & \\
$\quad$ Male & $453(90.2)$ \\
$\quad$ Female & $49(9.8)$ \\
Age & $\overline{\mathrm{x}}=38.5 \mathrm{yrs}$ \\
& $\mathrm{SD} \pm=7.9 \mathrm{yrs}$
\end{tabular}

\section{Highest Educational Degree}

High school diploma or GED

Some college or bachelor's degree

Some graduate school or graduate degree

Rank

Police Officer

$401(80.5)$

Sergeant

$60(12.0)$

$7(1.4)$

Detective Sergeant

$18(3.6)$

Detective Lieutenant

$6(1.2)$

Captain

$2(0.4)$

Deputy Inspector

$4(0.8)$

Chief

$\overline{\mathrm{X}}=9.4 \mathrm{yrs}$

Length of Time Affiliated with Current Organization

$\mathrm{SD} \pm=6.8 \mathrm{yrs}$

\section{Length of Time at Current Rank}

$\overline{\mathrm{x}}=7.2 \mathrm{yrs}$

$\mathrm{SD} \pm=5.6 \mathrm{yrs}$

\section{Assignment}

Administrative

Investigative

Patrol

$425(84.7)$

Specialty Unit (e.g., Emergency Services Unit)

$25(5.0)$

Command

Prior WMD Training

None

$1-5$ hrs

6-10 hrs

More than $10 \mathrm{hrs}$

Prior First-Responder Training

Yes

$445(88.6)$

No

Prior Response to Large-Scale Disaster or WMD Event

Yes

No

*Column numbers may not add to 502 due to missing values.

$\overline{\mathrm{x}}=$ Mean; SD = Standard Deviation. 
On average, participants had high scores ( 12.0 points out of a maximum of 13.0 points, or a score of $92 \%$ ) on the overall knowledge set of questions on the pre-test. This indicates a high baseline level of general WMD knowledge. Scores also were high on the pre-test for the subset of items related to recognition of WMD events (7.3/8.0, 91\%) and response to WMD scenarios (4.7/5.0, 94\%).

\section{Overall Knowledge Assessment}

Results of the dependent $t$-test indicated that there was a statistically significant mean difference between overall scores on the pretest and post-test, $t(501)=9.3$, $\mathrm{p}<0.001, \mathrm{~d}=0.41(95 \% \mathrm{Cl}=0.33-0.50)$. Assessment scores significantly increased immediately following training from pre-test (Mean $[M]=12.0$, Standard Deviation $[S D]=1.4)$ to post-test $(M=12.6, S D=0.9)$; thus, the training was effective at increasing knowledge. Furthermore, for individuals who completed all three waves of testing, knowledge was retained from the post-test $(M=12.7, S D=0.6)$ to follow-up $(M=12.6, S D=0.9)$, as there was no statistically significant difference between assessment scores, $t(107)=-1.14, p=0.26$. In terms of net gain in overall knowledge, there was a significant difference between assessment scores at pre-test and follow-up, $\mathrm{t}(107)=3.0, \mathrm{p}<0.01, \mathrm{~d}=0.45(95 \% \mathrm{Cl}=0.26-0.64)$, with assessment scores significantly increasing from pretest $(M=12.3, S D=1.1)$ to follow-up test $(M=12.6, S D=0.9)$.

\section{WMD Recognition}

For the eight-item WMD recognition scale there was also an increase in knowledge after training, $\mathrm{t}(501)=7.7, \mathrm{p}<.001, \mathrm{~d}=0.35(95 \% \mathrm{Cl}=0.26-0.43)$. Specifically, WMD recognition subscale scores significantly increased from pre-test $(M=7.3$, $S D=1.1)$ to post-test $(M=7.7, S D=0.7)$; thus, the training was effective at increasing WMD recognition knowledge. Knowledge of recognition of WMDs was also retained at follow-up; there was no statistically significant difference in recognition subscale scores at post-test $(M=7.7, S D=0.6)$ and follow-up test $(M=7.7, S D$ $=0.7), t(107)=-0.37, p=0.72$. Furthermore, scores on the recognition subscale did significantly increase from pre-test $(M=7.4, S D=1.0)$ to follow-up test $(M=7.7$, $\mathrm{SD}=0.7), \mathrm{t}(107)=2.65, \mathrm{p}<0.01, \mathrm{~d}=0.35(95 \% \mathrm{Cl}=0.16-0.54)$; thus, there was an overall net gain in WMD recognition knowledge for participants who completed the one-month follow-up. 


\section{WMD Response}

Results from the dependent $t$-test revealed a significant difference between WMD response subscale scores from pre-test $(M=4.7, S D=0.6)$ to post-test $(M=4.9$, $\mathrm{SD}=0.3), \mathrm{t}(501)=7.8, \mathrm{p}<0.001, \mathrm{~d}=0.35(95 \% \mathrm{Cl}=0.26-0.44)$; the training was effective at increasing WMD response-specific knowledge. In addition, knowledge of WMD response was retained from the post-test $(M=5.0, S D=0.1)$ to onemonth follow-up test $(M=4.9, S D=0.4)$, as there were no significant differences between subscale scores, $t(107)=-1.9, p=0.06$. Scores on the recognition subscale were not significantly different from pre-test $(M=4.8, S D=0.4)$ to follow-up test $(M=4.9, S D=0.4), t(107)=1.73, p=0.09$, indicating that there was no significant gain in WMD recognition knowledge from baseline to follow-up.

Participants whose length of time at their current position in the MTAPD was below the mean ( 7.2 years) were almost two times more likely to increase their knowledge of proper response to WMD scenarios from pre-test to post-test immediately following training in comparison with participants whose time at their current position was above the mean, $\mathrm{X}^{2}(1)=5.4, \mathrm{p}<0.05, \mathrm{OR}=1.9(95 \% \mathrm{Cl}$ $=1.1-3.3$ ).

\section{Scenario Simulations}

Regarding the 11 decision points in the simulation scenarios, on average, more than 90 percent of the participants made the correct decision points.

\section{Follow-up Test}

Follow-up tests were completed by 108 participants (22\%), and some differences were noted between participants who did not participate at follow-up and those who did. Police officers were two times less likely to complete one-month followup tests than MTAPD participants from all other ranks, $X^{2}(1)=8.2, p<0.01, O R=$ $2.0(95 \% \mathrm{Cl}=1.2-3.4)$. Participants with less than six hours of prior WMD training were almost two times less likely to complete the follow-up than participants with more prior training, $\mathrm{X}^{2}(1)=7.2, \mathrm{p}<0.01, \mathrm{OR}=1.8(95 \% \mathrm{Cl}=1.2-2.8)$. Furthermore, MTA police officers who never responded to a large scale disaster or WMD event were two times less likely to complete the follow-up than those who had prior disaster response, $\mathrm{X}^{2}(1)=10.6, \mathrm{p}=0.001, \mathrm{OR}=2.0(95 \% \mathrm{Cl}=1.3-3.1)$. Last, there was a difference in pre-test scores for police who followed-up and those who did not; police who did not follow-up tended to score lower on the pre-test ( $M=$ $12.0, \mathrm{SD}=1.4)$ than those who did follow-up $(M=12.3, \mathrm{SD}=1.1), \mathrm{t}(216.5)=2.0$, $\mathrm{p}<0.05, \mathrm{~d}=0.22(95 \% \mathrm{Cl}=0.007-0.43)$. No significant differences were found between police who completed the follow-up test and those who did not on age, 
gender, education, tenure with the MTAPD, length of time at their current position, current assignment, and prior first-responder training variables.

\section{Evaluation}

Participants ( $\mathrm{N}=502)$ provided very positive feedback on the program evaluation. A large majority (92\%) of police indicated that the training program reinforced their understanding of WMDs. Eighty-eight percent reported that the use of scenarios in the simulation exercises was especially helpful in improving their understanding of WMDs. Most of the sample (94\%) indicated that the training described realistic scenarios and events. Eighty-one percent of MTA police also indicated that they felt more confident in their ability to respond to a WMD event following this training.

\section{Discussion}

This web-based WMD preparedness training for transit police was effective in increasing knowledge. Increased knowledge scores (from pre-test to post-test) were noted for the overall assessment, WMD recognition items, and WMD response items. Furthermore, for participants who completed all three waves of testing, knowledge was retained for overall and domain-specific knowledge at the one-month follow-up. There was a net gain in knowledge (from pre-test to follow-up test) on the overall WMD assessment and WMD recognition items. Because the baseline level of knowledge was very high, the improvement was small, yet statistically significant. The estimates of internal consistency for the 13-item assessment and WMD recognition and WMD response subscales were tolerable, given the high scores on almost all baseline items (and thus limited variability). Consequently, a high alpha value was not expected, yet the results were still significant. In addition, this training program received a positive evaluation. Most participants felt the scenarios were realistic illustrations of WMD events and also helpful in reinforcing their knowledge and building their confidence. Future training should include more difficult test items at the pre-test level, as this will allow for more robust measures of improvement.

Although the training was generally effective for all demographic groups, it was especially so for participants with fewer years of tenure on the job. Therefore, the training program might be most appropriate for new recruits, and a more difficult, advanced program might be better suited for more seasoned officers. To improve 
follow-up testing response rates, better incentives might be used. If training and follow-up testing are mandatory, poor response rates may be eliminated.

\section{Limitations}

The study was conducted with transit police affiliated with the MTA in New York City, and these officers may have had more disaster response experience than transit police in other cities. Therefore, this program and its effectiveness may not be generalizable across all transit agencies in the United States. However, the basic WMD knowledge module and scenarios should be applicable across a wide range of agencies and cities, and further study of other urban police forces would be useful in documenting this.

\section{Conclusions}

The threat of transit terrorist attacks involving WMD and the potential vulnerability of transit systems worldwide make security and emergency response preparedness important. Training of transit police and first responders can help increase the safety and security of passengers and transit workers. The approach we describe here is an effective and low-cost method for training an urban transit police force on the general recognition and appropriate response to WMD events. This web-based training program, with embedded performance measures, could be adapted easily to fit the needs of other first responders, such as transit workers. It is also easily modifiable to meet the needs of individual transit police departments. Online training should also be supplemented with hands-on practice and refresher trainings to increase retention of knowledge.

\section{Acknowledgements}

The authors gratefully acknowledge the continued support of this project by Dr. Roy Vigneulle and Major Greg Rule of the United States Army Medical Research and Materiel Command, Captain Neal Naito of the Navy Bureau of Medicine and Surgery, Dr. Dario Gonzalez of the Fire Department of New York, Captain John Berlingieri of the Metropolitan Transportation Authority Police Department, the Regional Emergency Medical Services Council of New York and the New York State Emergency Management Office, and the efforts of Dr. Martin Sherman, Mr. Jason Morris, and Ms. Melissa Wong in the early development of the project. 


\section{References}

American Public Transportation Association. 2009. 2009 Public Transportation Fact Book [cited September 25 2009]. Available from http://www.apta.com/ gap/policyresearch/Documents/APTA_2009_Fact_Book.pdf.

Bolling, R., Y. Ehrlin, R. Forsberg, A. Ruter, V. Soest, T. Vikstrom, P. Ortenwall, and H. Brandstrom. 2007. KAMEDO report 90: Terrorist attacks in Madrid, Spain, 2004. Prehospital and Disaster Medicine 22(3): 252-257.

Cohen, J. 1988. Statistical Power Analysis for the Behavioral Sciences. 2nd ed. Hillsdale, NJ: Erlbaum.

Cole, H. P. 1994. Embedded performance measures as teaching and assessment devices. Occupational Medicine 9(2): 261-281.

Dolnik, A. 2007. Assessing the terrorist threat to Singapore's land transportation infrastructure. Journal of Homeland Security and Emergency Management 4(2): Article 4.

Fink, C. N. Y., B. D. Taylor, and A. Loukaitou-Sideris. 2005. From policy and response to system design and operations: Inter-governmental transit security planning in the US. Journal of Public Transportation 8(4): 1-16.

Home Office of the United Kingdom. 2009. Office for security and counter terrorism 2009 [cited September 28 2009]. Available from http://security.homeoffice. gov.uk/.

Idrose, A. M., W. A. W. Adnan, G. F. Villa, and A. H. A. Abdullah. 2007. The use of classroom training and simulation in the training of medical responders for airport disaster. Emergency Medicine Journal 24(1): 7-11.

Intelligence and Security Committee. 2009. Intelligence and security committee report into the London terrorist attacks on 7 July 20052006 [cited May 11 2009]. Available from http://www.cabinetoffice.gov.uk/media/cabinetoffice/ corp/assets/publications/reports/intelligence/isc_7july_report.pdf.

Jenkins, B. M., and F. Edwards-Winslow. 2003. Saving city lifelines: Lessons learned in the 9-11 terrorist attacks. San Jose, CA: Mineta Transportation Institute.

Jenkins, B. M., and L. N. Gersten. 2001. Protecting public surface transportation against terrorism and serious crime: Continuing research on best security practices. San José, CA: Mineta Transportation Institute. 
Litman, T. 2005. Terrorism, transit, and public safety: Evaluating the risks. Journal of Public Transportation 8(4): 33-45.

Mammen, D. 2007. Recovery efforts in New York after 9/11. Journal of Disaster Research 2(6): 502-503.

Metropolitan Transportation Authority. 2009. MTA police. State of New York 2009 [cited September 16 2009]. Available from http://www.mta.info/mta/police/ index.html.

Office of the New York State Comptroller. 2006. Status report: The progress of the Metropolitan Transportation Authority's capital security program. New York: 9-2006.

Office of the New York State Comptroller. 2008. Progress report: The MTA capital security program. New York: 6-2009.

Okumura, T., N. Ninomiya, and M. Ohta. 2003. The chemical disaster response system in Japan. Prehospital and Disaster Medicine 18(3): 189-192.

Sahm, C. 2006. Hard won lessons: Transit security: Safe Cities Project, Manhattan Institute.

SPSS advanced version 16.0.1. SPSS Inc., Chicago, IL.

Subbarao, I., W. F. Bond, C. Johnson, E. B. Hsu, and T. E. Wasser. 2006. Using innovative simulation modalities for civilian-based, chemical, biological, radiological, nuclear, and explosive training in the acute management of terrorist victims: A pilot study. Prehospital and Disaster Medicine 21(4): 272-275.

Summerhill, E. M., M. C. Mathew, S. Stipho, A. W. Artenstein, L. Jagminas, P. M. Russo-Magno, S. Potter, and M. J. Shapiro. 2008. A simulation-based biodefense and disaster preparedness curriculum for internal medicine residents Medical Teacher 30(6): 145-151.

Taylor, B. D., A. Loukaitou-Sideris, R. Liggett, C. Fink, M. Wachs, E. Cavanagh, C. Cherry, and P. J. Haas. 2005. Designing and operating safe and secure transit systems: Assessing current practices in the United States and abroad. San José, CA: Mineta Transportation Institute.

Waugh, W. L., Jr. 2004. Securing mass transit: A challenge for homeland security. Review of Policy Research 21(3): 307-316. 


\section{About the Authors}

LORI A. MAGDA (LAM2181@columbia.edu) is the data manager for Dr. Robyn Gershon's research group at the Mailman School of Public Health at Columbia University. She received her M.A. in Psychology in Education from Teachers College, Columbia University.

Allison N. CANTon (ANCanton@gmail.com) is the former research director for Dr. Robyn Gershon's research group at the Mailman School of Public Health at Columbia University. She holds a B.A. in Political Science from Amherst College and attends Harvard Law School.

*DR. ROBYn R.M. GerShON (RG405@columbia.edu) is professor of Clinical Sociomedical Sciences at the Mailman School of Public Health at Columbia University in New York City with a joint appointment in the School of Nursing. Her research interests include emergency preparedness and willingness of essential personnel to report to duty in the event of a pandemic. She holds a DrPH from the Bloomberg School of Public Health at Johns Hopkins University.

* Corresponding Author 